\title{
Effects of Inspiratory Muscle Training in Subjects With Sarcoidosis: A Randomized Controlled Clinical Trial
}

\author{
Müşerrefe Nur Karadallı MSc, Meral Boşnak-Güçlü PhD, Burcu Camcığlu MSc, \\ Nurdan Kokturk MD, and Haluk Türktaş MD
}

\begin{abstract}
BACKGROUND: Respiratory muscle weakness occurs in sarcoidosis and is related to decreased exercise capacity, greater fatigue, dyspnea, and lower quality of life in sarcoidosis patients. The effects of inspiratory muscle training in this population have not been comprehensively investigated so far. This study was planned to investigate the effects of inspiratory muscle training on exercise capacity, respiratory and peripheral muscle strength, pulmonary function and diffusing capacity, fatigue, dyspnea, depression, and quality of life in subjects with sarcoidosis. METHODS: This was a prospective, randomized, controlled, and double blind study. Fifteen sarcoidosis subjects (treatment group) received inspiratory muscle training at $40 \%$ of maximal inspiratory pressure $\left(P_{\text {Imax }}\right)$, and 15 subjects (control group) received sham therapy $\left(5 \%\right.$ of $P_{\text {Imax }}$ ) for 6 weeks. Functional and maximal exercise capacity, respiratory and peripheral muscle strength, pulmonary function and diffusing capacity, fatigue, dyspnea, depression, and quality of life were evaluated. RESULTS: Functional $(P<.001)$ and maximal exercise capacity $(P=.038)$, respiratory muscle strength $\left(P_{\text {Imax }}\right.$ $[P<.001]$ and $\left.P_{E \max }[P=.001]\right)$, severe fatigue $(P=.002)$, and dyspnea perception $(P=.02)$ were statistically significantly improved in the treatment group compared with controls; no significant improvements were observed in pulmonary function and diffusing capacity, peripheral muscle strength, fatigue, depression, and quality of life between groups after inspiratory muscle training. CONCLUSIONS: Inspiratory muscle training improves functional and maximal exercise capacity and respiratory muscle strength and decreases severe fatigue and dyspnea perception in subjects with early stages of sarcoidosis. Inspiratory muscle training can be safely and effectively included in rehabilitation programs. (ClinicalTrials.gov registration NCT02270333.) Key words: sarcoidosis; respiratory muscles; exercise; fatigue; dyspnea; quality of life. [Respir Care 2016;61(4):483-494. ( 2016 Daedalus Enterprises]
\end{abstract}

\section{Introduction}

Sarcoidosis is a multisystem disorder of unknown origin, and the clinical manifestations vary, depending on

\footnotetext{
Mr Karadallı, Dr Boşnak-Güçlü, and Mr Camcıoğlu are affiliated with the Faculty of Health Sciences, Department of Physiotherapy and Rehabilitation, and Drs Kokturk and Türktaş are affiliated with the Faculty of Medicine, Department of Pulmonary Medicine, Gazi University, Ankara, Turkey.
}

The authors have disclosed no conflicts of interest.

Correspondence: Müşerrefe Nur Karadallı, MSc, Gazi University, Faculty of Health Sciences, Department of Physiotherapy and Rehabilitation, Muammer Yaşar Bostancı Mah., No: 16, 06500 Beşevler, Ankara, Turkey. E-mail: muserref-1@ hotmail.com.

DOI: $10.4187 /$ respcare. 04312 organs involved. Additionally, nonspecific symptoms, such as exercise intolerance, peripheral and respiratory muscle weakness, fatigue, dyspnea, depression, and reduced quality of life, are also commonly seen. ${ }^{1}$

Exercise intolerance is a common problem in sarcoidosis and is related to several factors. Several studies have demonstrated that exercise intolerance is related to reduced quality of life and increased dyspnea and fatigue perception in subjects with sarcoidosis..$^{2,3}$

Involvement of the lung mechanics may result in increased respiratory work load. Even when lung function is normal, respiratory muscle strength is reduced in subjects with sarcoidosis, and respiratory muscle weakness increases dyspnea perception and impairs exercise capacity., ${ }^{2,4,5,6}$ One study ${ }^{4}$ reported inspiratory muscle weakness in $16.7 \%$ of subjects with stage I-IV sarcoidosis, and other studies $2,5,6$ have also shown that subjects' inspiratory muscle strength 
is decreased up to $45 \%$ and expiratory muscle strength is decreased up to $40 \%$ when compared with healthy controls. Kabitz et $\mathrm{al}^{4}$ demonstrated that inspiratory muscle strength is strongly predictive for dyspnea and functional exercise capacity.

Lung function tests are commonly used to interpret the disease progress in patients with sarcoidosis. Whereas lung function test abnormalities are observed in $20 \%$ of stage I patients, this rate increases up to $40-80 \%$ in stage II-IV patients. Reduced diffusing capacity of the lung for carbon monoxide $\left(\mathrm{D}_{\mathrm{LCO}}\right)$ is especially seen in the late stages of the disease. ${ }^{7}$

Fatigue and dyspnea are some of the most prevalent symptoms in sarcoidosis; 30-90\% of subjects report severe fatigue perception. ${ }^{3,8}$ Although resting dyspnea is not generally prevalent, exercise-induced dyspnea is especially perceived in stage II-IV of sarcoidosis and correlates with reduced respiratory muscle strength. ${ }^{4,5}$ Indeed, all of these symptoms affect patients' quality of life. Reduced quality of life was shown to be related to lower physical activity levels, fatigue, depression, dyspnea, and social isolation. ${ }^{6,9}$

A limited number of studies have investigated respiratory muscle weakness and its effects on clinical symptoms in sarcoidosis. Respiratory muscle weakness is related to increased fatigue and dyspnea perception and reduced exercise capacity and health status. ${ }^{4-6,9}$ Meta-analyses of randomized controlled trials and systematic reviews on COPD,${ }^{10,11}$ asthma, ${ }^{12}$ bronchiectasis, ${ }^{13}$ cystic fibrosis, ${ }^{14}$ and heart failure ${ }^{15}$ have shown the beneficial effects of inspiratory muscle training on several outcomes.

Although the evidence in the current literature supports the benefits of inspiratory muscle training, there is, to our knowledge, no study investigating the effects of inspiratory muscle training in subjects with sarcoidosis. This study aimed to examine the effects of inspiratory muscle training on exercise capacity, respiratory and peripheral muscle strength, pulmonary function and diffusing capacity, fatigue, dyspnea, depression, and quality of life in subjects with sarcoidosis. Thus, the present study hypothesized that inspiratory muscle training would improve the aforementioned outcomes in subjects with sarcoidosis.

\section{Methods}

\section{Subjects}

Between June 2012 and March 2014, 30 subjects with sarcoidosis referred to the Gazi University Faculty of Health Sciences, Department of Physiotherapy and Rehabilitation, were included. Subjects were diagnosed with sarcoidosis according to the criteria of the latest American Thoracic Society/European Respiratory Society/World Association of Sarcoidosis and Other Granulomatous Disorders statement on sarcoidosis. ${ }^{1}$ The inclusion criteria

\section{QUICK LOOK}

\section{Current knowledge}

Sarcoidosis is a systemic granulomatous disorder of unknown origin that primarily impacts lungs and respiratory mechanics. Respiratory muscle weakness is a frequent symptom that impairs exercise capacity, health status, dyspnea, and fatigue perception in subjects suffering from sarcoidosis. The effects of improving muscle strength on outcomes in sarcoidosis are unclear.

\section{What this paper contributes to our knowledge}

Following a 6-week moderate intensity, thresholdloaded inspiratory muscle training program, maximal and submaximal exercise capacity, inspiratory and expiratory muscle strength, severe fatigue, and dyspnea perception were improved in subjects with sarcoidosis without any adverse effect.

were: being clinically stable (no exacerbations of sarcoidosis), radiological classification stage I-IV, and no change in medications over the last 3 months. The exclusion criteria were: cognitive disorders, taking a corticosteroid, having a co-morbidity to a degree that would prevent the application of inspiratory muscle training, acute infection, previously receiving pulmonary rehabilitation, receiving non-standard medical therapy, and orthopedic and neurological problems. The study was approved by the Ethics Committee of the University and performed in accordance with the Declaration of Helsinki. Written informed consent was obtained from all subjects to participate in the study.

\section{Study Design}

This was a prospective, randomized, controlled, and double blind study. Subjects were randomly allocated to either a treatment group receiving inspiratory muscle training or a control group receiving sham training for 6 weeks. Computer-generated random numbers were used for simple randomization of the subjects. Before and after the inspiratory muscle training, functional and maximal exercise capacity, respiratory and peripheral muscle strength, pulmonary function, dyspnea and fatigue perception, depression, and quality of life were evaluated. None of the subjects had received pulmonary rehabilitation before.

\section{Blinding}

Neither the investigator who collected pre- and posttreatment data nor the subjects were aware of whether they 
had been allocated to the treatment group or control group. Evaluations and treatments were performed by different physiotherapists. Subjects in different groups trained at different places and times.

\section{Measurements}

\section{Functional Exercise Capacity}

The 6-min walk test (6MWT) was performed in a 30-m unobstructed corridor. Measurement was done according to American Thoracic Society guidelines. ${ }^{16}$ Heart rate was monitored using an FT1-100 heart rate monitor (Polar Instruments, Shanghai, China) during the test. A modified Borg dyspnea scale was used before and after. The 6MWT was repeated 2 times, and the result was expressed as a percentage of the predicted values. ${ }^{17}$ Subjects rested for $30 \mathrm{~min}$ between the tests, and the highest distance was recorded. The minimum clinically important difference for 6MWT is $30-33$ m. ${ }^{18}$

\section{Maximal Exercise Capacity}

A modified incremental shuttle walk test was used to evaluate maximal exercise capacity. ${ }^{19}$ Subjects were instructed to walk/run up and down a 10-m course marked by cones placed $0.5 \mathrm{~m}$ from each end. The speed was controlled by signals from an audio tape recorder. The walking speed was progressively increased at 1-min intervals for a total of 15 stages. The test was terminated if the subject felt too breathless to continue at the desired speed, failed to complete a $10-\mathrm{m}$ length (shuttle) in the time allowed, or reached the predicted maximum heart rate. ${ }^{19}$ Modified incremental shuttle walk test distance was expressed as a percentage of the predicted values. ${ }^{20}$ Heart rate was monitored with an FT1-100 monitor. The modified Borg dyspnea scale was used, and breathing frequency and $\mathrm{S}_{\mathrm{pO}_{2}}$ were measured (pulse oximetry) during tests.

\section{Respiratory Muscle Strength}

Maximal inspiratory pressure $\left(\mathrm{P}_{\mathrm{Imax}}\right)$ and maximal expiratory pressure $\left(\mathrm{P}_{\mathrm{Emax}}\right)$ were assessed using an electronic pressure transducer (MicroRPM, Micromedical, Kent, United Kingdom). Measurements were done according to American Thoracic Society/European Respiratory Society statements. ${ }^{21}$ The $\mathrm{P}_{\text {Imax }}$ at residual volume and $\mathrm{P}_{\mathrm{Emax}}$ from total lung capacity were measured while the subjects were sitting, a minimum of 10 maneuvers were performed, and reference values were used for the comparison. ${ }^{22}$ Pressures were maintained for at least $1 \mathrm{~s}$, and the highest technically satisfactory measurement was recorded (within 5\%) and expressed in $\mathrm{cm}_{2} \mathrm{O}$.

\section{Peripheral Muscle Strength}

Quadriceps femoris and biceps brachii isometric muscle strength (non-dominant) were measured using a handheld dynamometer (Commander PowerTrack II, JTECH Medical, Midvale, Utah), which is regarded as reliable and valid method. ${ }^{23}$

\section{Pulmonary Function Tests}

Spirometric measurement was performed using a Vmax 220 spirometer (Sensormedics Corporation, Yorba Linda, California) according to the guidelines of the American Thoracic Society. ${ }^{24} \mathrm{FEV}_{1}$, FVC, $\mathrm{FEV}_{1} / \mathrm{FVC}$, peak expiratory flow, forced expiratory flow from 25 to $75 \%$, and $\mathrm{D}_{\text {LCO }}$ were expressed as percentages of the predicted values. $^{25,26}$

\section{Fatigue}

Fatigue was evaluated using the Turkish version of the Fatigue Severity Scale, ${ }^{27}$ a self-administered questionnaire consisting of 9 items. Subjects were asked to rate their level of agreement with 9 statements, each item scored from 0 (strong disagreement) to 7 (strong agreement). A score of $\geq 36$ indicated severe fatigue. ${ }^{27}$

\section{Dyspnea}

The Modified Medical Research Council dyspnea scale was used to evaluate dyspnea severity during activity, graded from 0 (absence of dyspnea during strenuous exercise) to 4 (dyspnea during daily activities). ${ }^{28}$

\section{Depression}

Depression severity was evaluated using the Turkish version of the Montgomery-Åsberg Depression Rating Scale. ${ }^{29}$ The scale consists of 10 items, the score for each item ranging from 0 to 6 . Low scores implied mild depression, whereas high scores implied severe depression. ${ }^{29}$

\section{Quality of Life}

Quality of life was assessed using the Turkish version of the St George Respiratory Questionnaire (SGRQ), ${ }^{30}$ containing 76 items with weighted responses covering 3 components: symptoms, activity, and impacts. The latter 2 relate to the subject's current state of health. All component items can be aggregated into a total SGRQ score. Scores range from 0 to 100 , with higher scores indicating poorer health status. ${ }^{30}$ 


\section{Inspiratory Muscle Training Protocol}

Training was performed using a pressure thresholdloading device (POWERbreathe Classic, IMT Technologies Ltd, Birmingham, United Kingdom) used to inhale against a same-pressure load every inhalation for strengthening primarily the diaphragm and rib cage muscles. ${ }^{31}$ The device pressure is adjusted according to $\mathrm{P}_{\text {Imax }}$, and reliability/reproducibility has been demonstrated. ${ }^{31,32}$ Subjects were given a 1-week familiarization period and instructed to learn diaphragmatic breathing adequately. The treatment group received inspiratory muscle training at $40 \%$ of $\mathrm{P}_{\text {Imax }}$, and training loads were adjusted to maintain $40 \%$ of the $\mathrm{P}_{\text {Imax }}$ weekly. The $\mathrm{P}_{\text {Imax }}$ was measured at supervised sessions each week, and $40 \%$ of the measured value was determined as the new training work load. The control group received sham inspiratory muscle training at a fixed work load, 5\% of $\mathrm{P}_{\text {Imax }}$. Subjects were instructed to maintain diaphragmatic breathing for $10-15$ breaths with a rest of 5-10 s between breaths. As soon as the subjects were able, they were encouraged to maintain $25-30$ breaths at each work load. Groups were trained for a total of $30 \mathrm{~min} / \mathrm{d}$, 7 days/week, for 6 weeks. Subjects in each group performed 6 sessions at home and 1 session under supervision at the Department of Physiotherapy and Rehabilitation. One day each week, the subjects' heart rate, blood pressure, and breathing frequency were monitored during the inspiratory muscle training sessions, and a new work load was given, which was adjusted to $40 \%$ of the highest $\mathrm{P}_{\text {Imax }}$ value newly measured at each week in the treatment group. Subjects were checked by telephone calls 2 times/week, to verify that they were performing the inspiratory muscle training correctly. Total minutes spent during the training period were calculated based on reports written in diaries. Subjects were told not to change pressure loads themselves and were instructed not to exercise or do physical activity over their normal routine during the study period.

\section{Statistical Analysis}

All statistical analyses were performed using SPSS 15.0 (SPSS, Chicago, Illinois). Based on the results of a previous study, ${ }^{18}$ we estimated that a sample size of 15 subjects/group would have a power of $80 \%$ to detect a 30-33-m difference in 6MWT distance for an $\alpha$ value of 0.05. Data normality was tested using the Shapiro-Wilk/ Kolmogorov-Smirnov test. Baseline characteristics of the groups were compared using a Student $t$ test, and differences were reported as mean difference and 95\% CI. Nominal data were compared using a chi-square test. Analysis of covariance was used to determine whether significant differences existed between pre- and post-test conditions (lung function, respiratory and peripheral muscle strength,

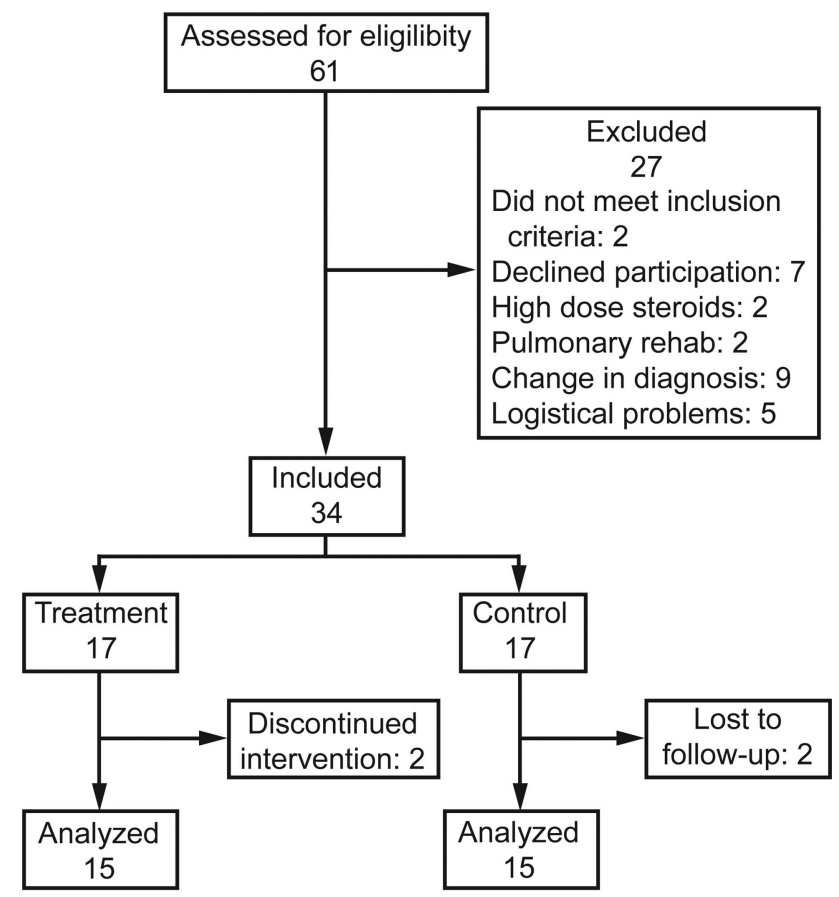

Fig. 1. Flow chart.

6MWT and modified incremental shuttle walk test distance, dyspnea, fatigue, depression, quality of life) and between the treatment and control groups, with baseline measurements used as covariates in the analysis. Manually adjusted post hoc comparisons were done using the Bonferroni test for the change in continuous variables within groups. A $P$ value of $\leq .05$ was considered as statistically significant. Severe fatigue perception was compared using the Cochran Q test. Effect sizes for the magnitude of statistically significant group differences were calculated using the Cohen $d$ statistic, and effect sizes were expressed as small $(>0.20)$, moderate (between 0.50 and 0.80 ), and large $(>0.80)$. Post hoc statistical power was calculated using GPower software according to 6MWT values. ${ }^{33}$ Training efficiency, expressed as the mean improvement in $\mathrm{P}_{\text {Imax }} / \mathrm{h}$ of time spent training (expressed as $\mathrm{cm} \mathrm{H}_{2} \mathrm{O} \times \mathrm{h}^{-1}$ ), was calculated.

\section{Results}

Sixty-one patients with sarcoidosis were screened for the study, and 27 patients were excluded because of the reasons presented (Fig. 1). Thirty-four subjects were assigned to either the treatment group or the control group; 15 subjects in each group completed the study. Based on the findings of chest radiographs, 9 subjects $(30 \%)$ presented with stage I sarcoidosis, and 21 subjects $(70 \%)$ presented with stage II. No subjects had any other organ system involvement. All subjects tolerated inspiratory mus- 
Table 1. Baseline Demographic Characteristics of Treatment and Control Groups

\begin{tabular}{lcrr}
\hline \hline \multicolumn{1}{c}{ Characteristics } & Treatment Group & Control Group & Mean Difference (95\% CI) \\
\hline Age, mean \pm SD y & $45.1 \pm 8.1$ & $47.5 \pm 12.9$ & $-2.4(-10.5$ to 5.7$)$ \\
Stage I/II, $n(\%)$ & $2(13.3) / 13(86.7)$ & $7(46.7) / 8(53.33)$ & .55 \\
Male/female, $n(\%)$ & $5 / 10(33.3 \% / 66.7 \%)$ & $6 / 9(40 \% / 60 \%)$ & .11 \\
Weight, mean \pm SD kg & $76.2 \pm 16.2$ & $77.5 \pm 14.1$ & .71 \\
Height, mean \pm SD cm & $167.5 \pm 8.7$ & $161.9 \pm 7.0$ & $-1.3(-12.7$ to 10.0$)$ \\
BMI, mean \pm SD kg/m ${ }^{2}$ & $27.0 \pm 5.1$ & $29.3 \pm 4.8$ & $5.7(-0.2$ to 11.6$)$ \\
Smoking, mean \pm SD pack-years & $14.9 \pm 12.1$ & $9.0 \pm 8.1$ & $-2.3(-6.0$ to 1.4$)$ \\
Non-smokers/ex-smokers, $n(\%)$ & $7(46.7 \%) / 8(53.3 \%)$ & $9(60 \%) / 6(40 \%)$ & $5.9(-6.6$ to 18.4$)$
\end{tabular}

BMI $=$ body mass index

cle training without any complaints, and no adverse effects occurred. Adherence to the training regimen was high in both groups. There was no significant difference between groups in time spent during inspiratory muscle training; the treatment group spent $1,189.0 \pm 45.0 \mathrm{~min}(94.4 \pm 3.6 \%$ of expected), and the control group spent $1,105.5 \pm 82.7 \mathrm{~min}$ ( $87.7 \pm 5.6 \%$ of expected). All of the data were normally distributed.

\section{Baseline Characteristics}

Groups were statistically similar in terms of demographic and clinical characteristics before inspiratory muscle training (Tables 1-4).

\section{Functional and Maximal Exercise Capacity}

The distance covered during 6MWT $(54.5 \mathrm{~m}$, 95\% CI 23.6-85.4 m, Cohen's $d=1.38$, large) and percent-of-predicted 6MWT distance (8.0\%, 95\% CI 3.9-12.1\%) significantly improved within the treatment group and compared with the control group (Table 3 and Figs. 2 and 3). No significant changes were observed in vital signs during 6MWT between groups (Table 3 ). The power of this study is $(1-\beta)=93.7 \%$. The distance covered during the modified incremental shuttle walk test $(45.4 \mathrm{~m}, 95 \%$ CI $2.7-$ $88.2 \mathrm{~m}$, Cohen's $\mathrm{d}=1.53$, large) significantly improved within the treatment group and compared with the control group, and percent-of-predicted modified incremental shuttle walk distance $(4.0 \%, 95 \%$ CI -1.2 to $9.2 \%)$ significantly improved within the treatment group (Table 3). Peak heart rate was significantly increased, and Borg dyspnea perception decreased in the treatment group compared with the control group, and percentage of peak heart rate and change in heart rate were significantly increased within the treatment group during the modified incremental shuttle walk test (Table 3).

\section{Inspiratory and Expiratory Muscle Strength}

Improvements in $\mathrm{P}_{\text {Imax }}\left(31.6 \mathrm{~cm} \mathrm{H}_{2} \mathrm{O}, 95 \%\right.$ CI 22.0 $41.1 \mathrm{~cm} \mathrm{H}_{2} \mathrm{O}$, Cohen's $\mathrm{d}=1.85$, large), percent-of-predicted $\mathrm{P}_{\text {Imax }}$, $\mathrm{P}_{\text {Emax }}\left(28.0 \mathrm{~cm} \mathrm{H}_{2} \mathrm{O}\right.$, 95\% CI 13.0 $43.1 \mathrm{~cm} \mathrm{H} \mathrm{H}_{2} \mathrm{O}$, Cohen's $\mathrm{d}=2.63$, large), and percent-ofpredicted $\mathrm{P}_{\mathrm{Emax}}$ were significantly greater in the treatment group compared with the control group (Table 2 and Figs. 4 and 5). The inspiratory muscle training resulted in a mean improvement of $2.4 \pm 0.7 \mathrm{~cm} \mathrm{H}_{2} \mathrm{O} \times \mathrm{h}^{-1}$ in $\mathrm{P}_{\text {Imax }}$ in the treatment group and $0.71 \pm 0.68 \mathrm{~cm} \mathrm{H}_{2} \mathrm{O} \times \mathrm{h}^{-1}$ in the control group $(P<.001)$.

\section{Peripheral Muscle Strength}

There were no significant differences in quadriceps femoris $(24.2$ newtons, $95 \%$ CI -22.2 to $70.6 \%$, Cohen's $\mathrm{d}=0.48$, small) and biceps brachii muscle strength (19.2 newtons, $95 \%$ CI -16.0 to $54.3 \%$, Cohen's $\mathrm{d}=1.06$, large) between the groups after inspiratory muscle training. However, there was a significant difference in biceps brachii muscle strength within the treatment group (Table 2).

\section{Pulmonary Function}

There were no significant differences in percent-of-predicted $\mathrm{FEV}_{1}, \mathrm{FVC}, \mathrm{FEV}_{1} / \mathrm{FVC}$, forced expiratory flow from 25 to $75 \%$, peak expiratory flow, and $\mathrm{D}_{\mathrm{LCO}}$ between groups (Table 2) after inspiratory muscle training.

\section{Fatigue}

There was no significant difference in fatigue between groups $(1.5,95 \% \mathrm{CI}-6.8$ to 9.9 , Cohen's $\mathrm{d}=1.18$, large), but significant differences were present within groups (Table 4) after inspiratory muscle training. There was a significant reduction in severe fatigue perception between groups $(P=.002)$ and within the treatment group 


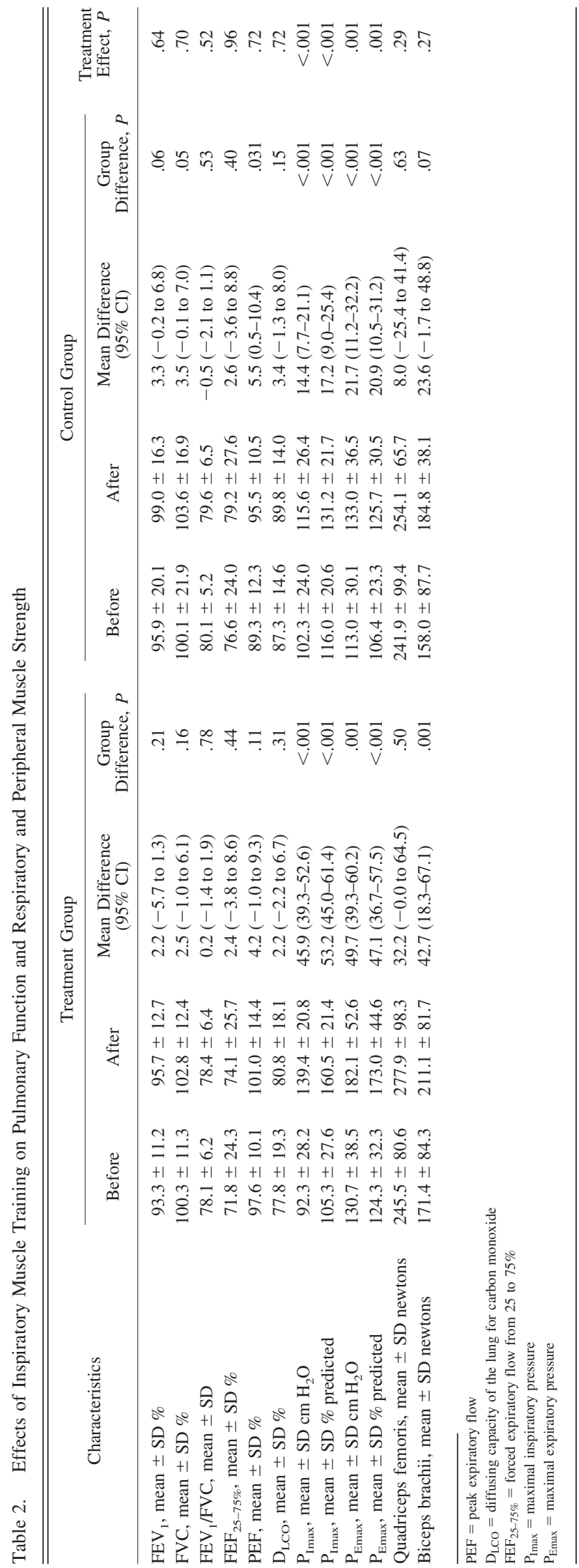

(from 10 [66.7\%] to 5 subjects [33.3\%], $P=.03$, in the treatment group; from 11 [73.3\%] to 6 subjects [40\%], $P=.13$, in the control group).

\section{Dyspnea}

Functional dyspnea significantly improved in the treatment group compared with the control group $(-0.4,95 \% \mathrm{CI}=-0.8$ to -0.1 , Cohen's $d=2.63$, large) and within groups (Table 4) after inspiratory muscle training.

\section{Depression}

There was no significant decrease in depression between groups $(-0.4,95 \% \mathrm{CI}-3.5$ to 2.7 , Cohen's $\mathrm{d}=2.9$, large), but there was a significant decrease within groups after inspiratory muscle training (Table 4).

\section{Quality of Life}

There were no significant differences in SGRQ quality of life scores between groups: symptoms $(-4.0$, $95 \% \mathrm{CI}-15.3$ to 7.4 , Cohen's $\mathrm{d}=1.47$, large), activity $(-0.7,95 \% \mathrm{CI}-12.3$ to 10.9 , Cohen's $\mathrm{d}=1.0$, large $)$, impact $(-1.7,95 \% \mathrm{CI}-11.5$ to 8.2 , Cohen's $\mathrm{d}=0.88$, large $)$, total $(-1.8,95 \% \mathrm{CI}=-10.5$ to 6.8 , Cohen's $\mathrm{d}=1.31$, large). However, there was significant improvement within groups (Table 4) after inspiratory muscle training.

\section{Discussion}

The most important results of the present study are: A 6-week inspiratory muscle training program improved maximal (12.0\%) and submaximal (14.1\%) exercise capacity and respiratory $\left(\mathrm{P}_{\operatorname{Imax}}=56.2 \%, \mathrm{P}_{\mathrm{Emax}}=41.1 \%\right)$ muscle strength and decreased severe fatigue and dyspnea perception in subjects with early stages of sarcoidosis. The present study has an adequate sample size, control group, double blinding, and high study power (93.7\%) to support our hypothesis. The 6-week inspiratory muscle training program did not have an impact on pulmonary function and diffusing capacity, peripheral muscle strength, fatigue, depression, and quality of life. The finding that the effect size indicated small and large treatment effects for peripheral muscle strength, fatigue, and quality of life (with low statistical power) suggests that a 6-week inspiratory muscle training work load/duration may not be long enough to improve these parameters, or the sample size may not be adequate to detect the improvement in the aforementioned outcomes. We also reported the effect size of variables that are useful for determining the practical or theoretical importance of an effect, the relative contributions of factors, and the power of an analysis. Our study has additional 
Inspiratory Muscle Training In SARCoIdosis

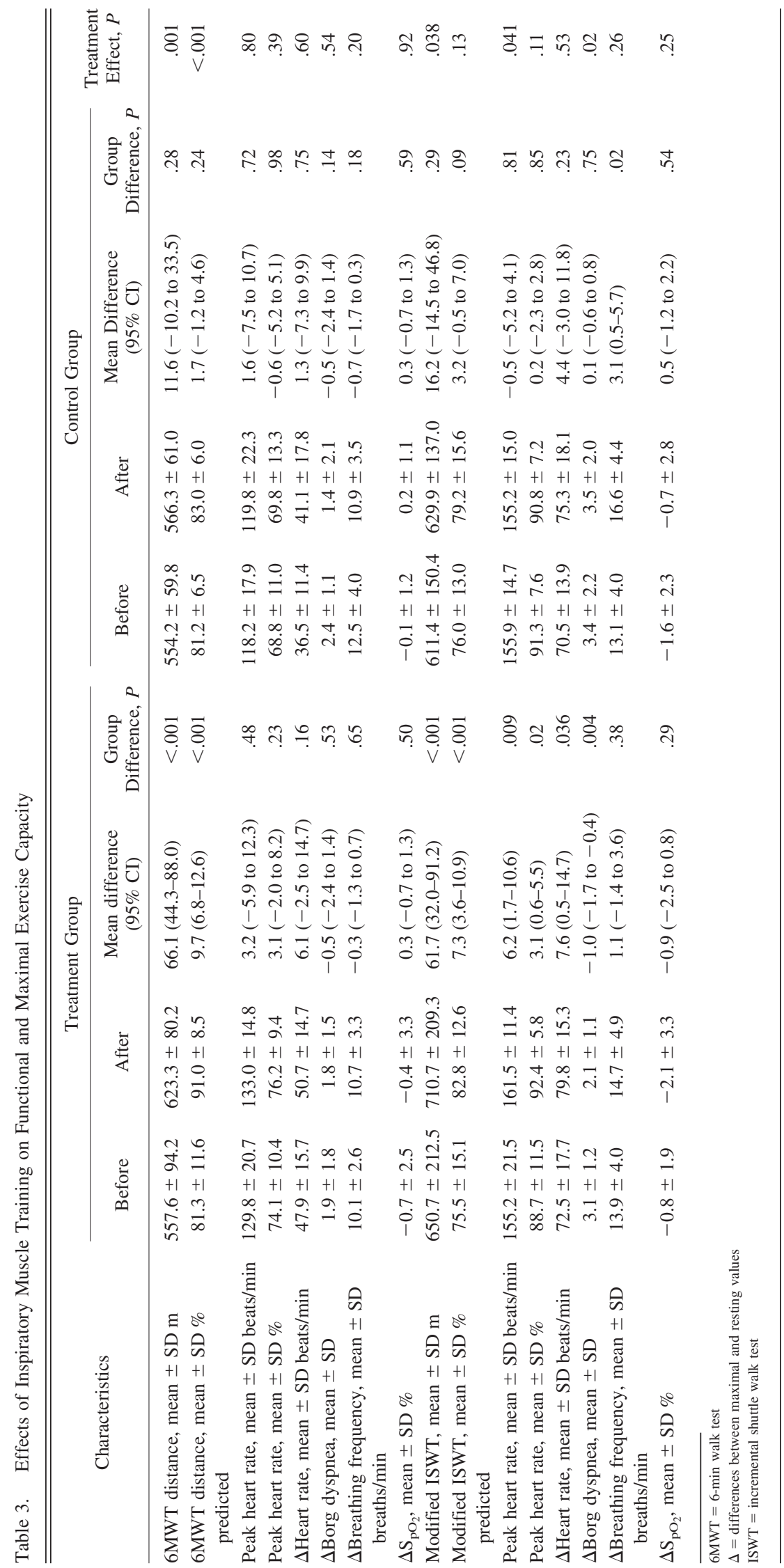




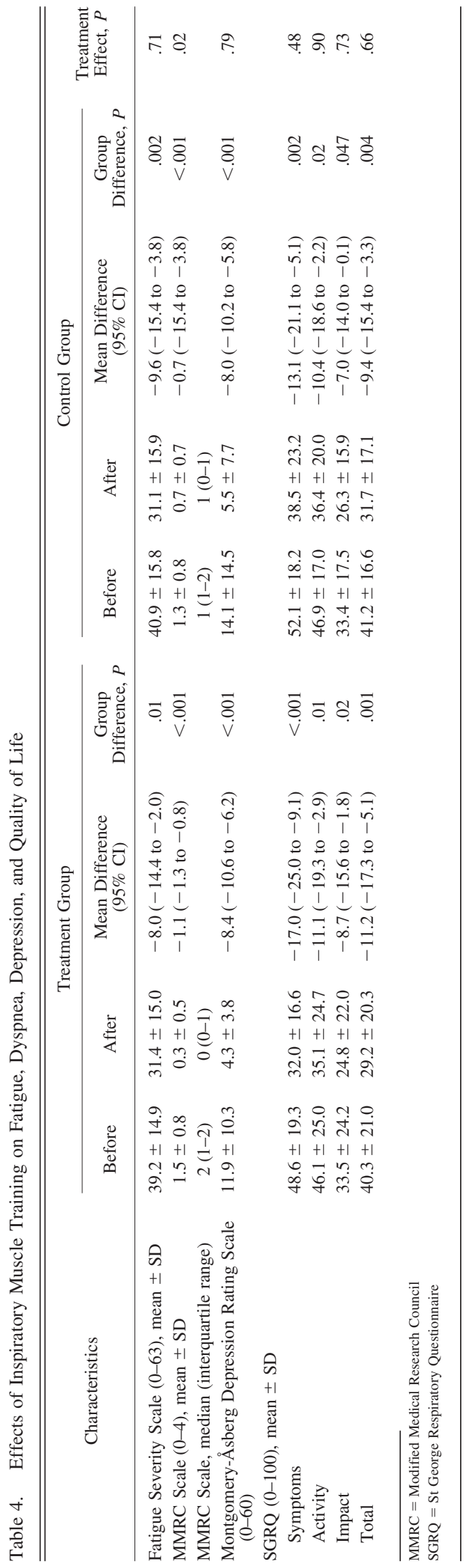

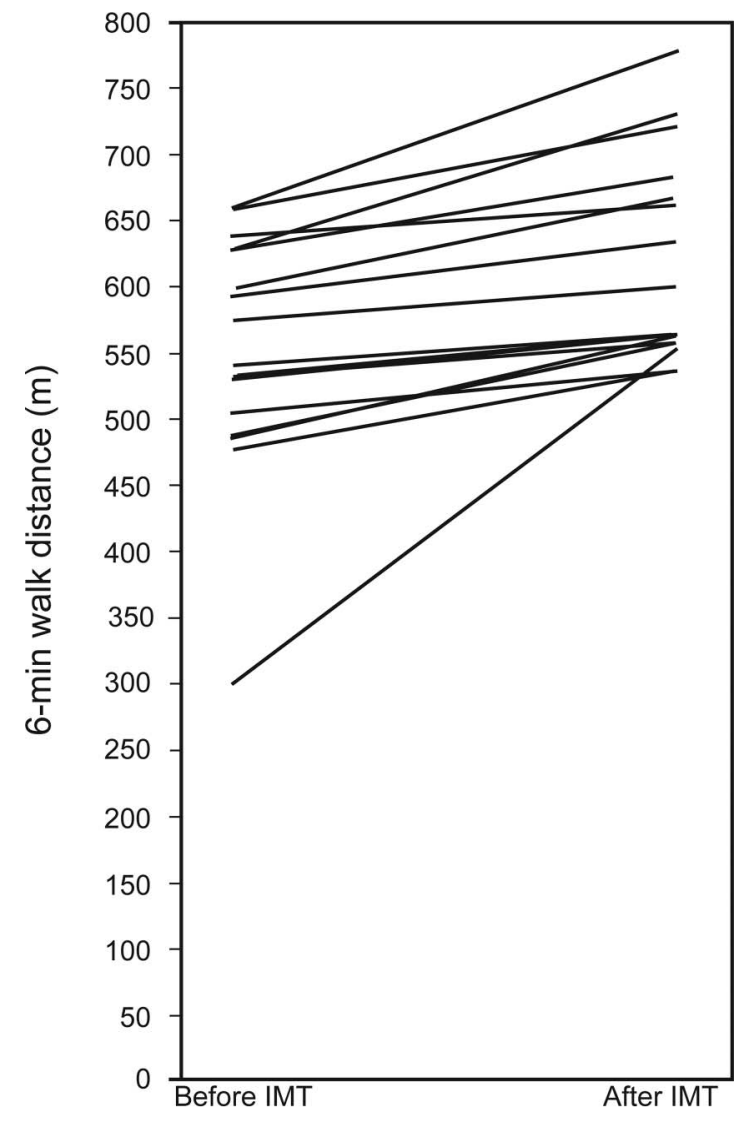

Fig. 2. 6-min walk distance before and after inspiratory muscle training in the treatment group.

advantages, such as the application of a 1-week familiarization period before inspiratory muscle training and monitoring of subjects' adherence to the training regimen.

\section{Functional and Maximal Exercise Capacity}

This study is the first to investigate the effects of inspiratory muscle training on functional exercise capacity in subjects with sarcoidosis, and the distance covered during the 6MWT $(54.51 \mathrm{~m})$ increased with large effect sizes. Inspiratory muscle training has become a popular training method in recent years and is used in a wide range of clinical conditions. Consistent with our findings, prior studies showed significant improvement in functional exercise capacity following mild to moderate intensity inspiratory muscle training in subjects with COPD, cystic fibrosis, asthma, bronchiectasis, or heart failure and healthy individuals. ${ }^{10-15}$ Inspiratory muscle training has been shown to improve cycling endurance, exercising lactate levels, diaphragm thickness, and inspiratory muscle strength in previous studies. ${ }^{34-39}$ Findings in the literature serve as possible 


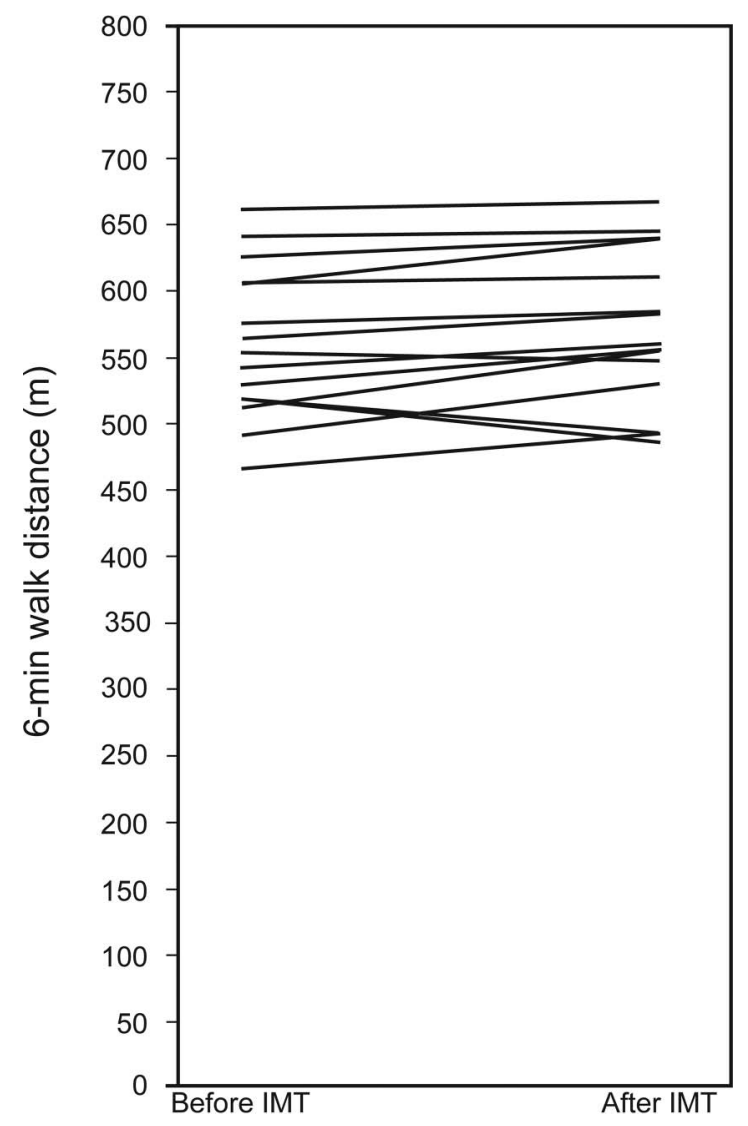

Fig. 3. 6-min walk distance before and after inspiratory muscle training in the control group.

explanations for the large improvement in exercise capacity. In the literature, we also noted descriptions of the effects of inspiratory muscle training on maximal exercise capacity; modified incremental shuttle walk test distance improved $(45.4 \mathrm{~m})$ with remarkably large effect sizes in subjects with sarcoidosis after inspiratory muscle training. Sánchez Riera et $\mathrm{al}^{35}$ demonstrated significant improvement in a modified incremental shuttle walk test $(93 \mathrm{~m})$ in COPD after inspiratory muscle training, where the improvement in distance is higher than ours $(45.4 \mathrm{~m})$. Greater distance improvement covered by subjects who underwent training in our study can be attributed to desensitization to dyspnea as a result of inspiratory muscle training. Additionally, peak heart rate and Borg dyspnea levels during the modified incremental shuttle walk test also improved, consistent with the findings of Sánchez Riera et al, ${ }^{35}$ which suggest that inspiratory muscle training improves heart rate response and dyspnea perception during maximal exercise in sarcoidosis subjects. Our findings serve as valuable evidence supporting the implementation of inspiratory muscle training as non-pharmacologic treatment of sarcoidosis to improve submaximal and exercise capacity in patients with sarcoidosis.

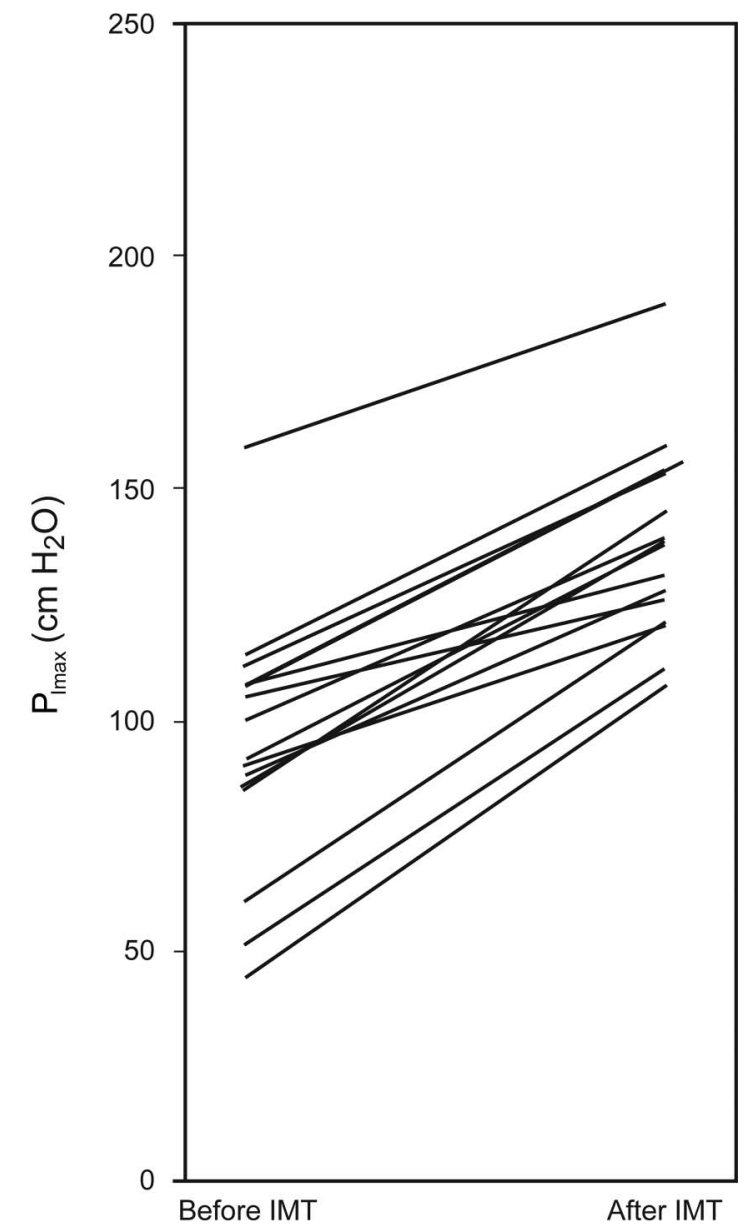

Fig. 4. Maximal inspiratory pressure $\left(P_{\text {Imax }}\right)$ before and after inspiratory muscle training in the treatment group.

\section{Inspiratory and Expiratory Muscle Strength}

Our study included subjects in the early stages of sarcoidosis, $13.3 \%$ of subjects in the treatment group and $20 \%$ in the control group had inspiratory muscle weakness $\left(\mathrm{P}_{\text {Imax }}\right.$ and $\mathrm{P}_{\text {Emax }}$ of $\left.\leq 80 \mathrm{~cm} \mathrm{H}_{2} \mathrm{O}\right) .{ }^{21}$ The inspiratory muscle training was applied for $30 \mathrm{~min} / \mathrm{d}, 7$ days/week, for 6 weeks, and respiratory muscle strength consistently improved with a large treatment effect. Prior studies also demonstrated that inspiratory muscle training improves inspiratory and expiratory muscle strength in various patient populations, ${ }^{11-13,36}$ similar to our findings.

\section{Peripheral Muscle Strength}

Peripheral muscle weakness is a common clinical manifestation in sarcoidosis and is affected by confounding factors, such as fatigue, physical inactivity, or reduced quality of life. ${ }^{2}$ Quadriceps femoris muscle strength improved in subjects with heart failure after inspiratory muscle training, as reported previously. ${ }^{36}$ Inconsistent with the 


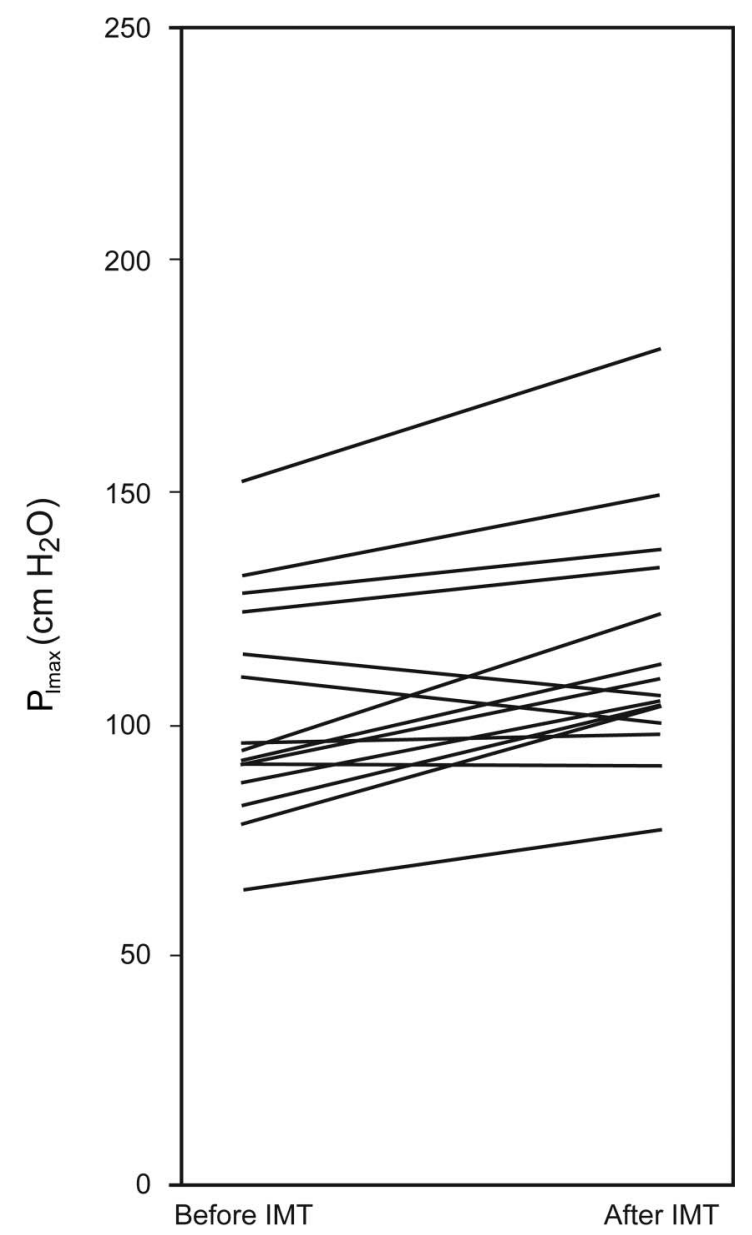

Fig. 5. Maximal inspiratory pressure $\left(P_{\text {Imax }}\right)$ before and after inspiratory muscle training in the control group.

previous report, ${ }^{36}$ inspiratory muscle training resulted in no improvement in quadriceps femoris and biceps brachii muscle strength in our study. Combined aerobic, resistance training, and inspiratory muscle training resulted in improved peripheral muscle strength compared with aerobic training in subjects with chronic heart failure and cystic fibrosis. ${ }^{37,38}$ Whether the application of higher intensity and/or longer duration training or a combination of inspiratory muscle training with aerobic/resistance training might provide a treatment effect on peripheral muscle strength in recipients should be investigated.

\section{Pulmonary Function}

Numerous findings on various diseases have shown no change in dynamic lung volumes after inspiratory muscle training, ${ }^{11-15}$ consistent with our findings. We also investigated the effects of inspiratory muscle training on $\mathrm{D}_{\mathrm{LCO}}$ and observed no improvement. On the other hand, inspiratory muscle training improved vital capacity and total lung capacity in subjects with cystic fibrosis. ${ }^{39}$ Further studies investigating the effects of inspiratory muscle training on both static and dynamic lung volumes and $\mathrm{D}_{\mathrm{LCO}}$ in subjects with sarcoidosis will be beneficial.

\section{Fatigue and Depression}

Inspiratory muscle training has been shown to improve fatigue in previous studies. ${ }^{35,39}$ In contrast to previous studies, no improvement was seen in fatigue and depression in our study. However, inspiratory muscle training resulted in improvement in severe fatigue perception. Previous studies have also reported that fatigue is a commonly seen, important clinical symptom that has to be treated in patients with sarcoidosis. Hill et $\mathrm{al}^{40}$ reported that high-intensity inspiratory muscle training resulted in clinical improvement in fatigue perception.

Major depressive disorder prevalence is as high as 70\% and is associated with impaired pulmonary function and increase dyspnea perception in sarcoidosis subjects. ${ }^{1-3,8}$ Inspiratory muscle training has been shown to improve depression in previous studies. ${ }^{36,39}$ Although depression was alleviated in both groups, a higher inspiratory muscle training work load was not superior to the lower work load in the present study. Enright et a ${ }^{139}$ found that higher work loads of inspiratory muscle training $\left(80 \%\right.$ of $\left.\mathrm{P}_{\text {Imax }}\right)$ resulted in improvement in depression in subjects with cystic fibrosis. Applying higher intensity and/or longer duration inspiratory muscle training may provide a treatment effect on fatigue and depression in patients with sarcoidosis. Fatigue and depression in patients with sarcoidosis is multifactorial, so effects of inspiratory muscle training on mechanisms that would alleviate these outcomes should also be investigated.

\section{Dyspnea}

Consistent with the previous studies, ${ }^{10-12}$ inspiratory muscle training improved dyspnea perception in daily activities in our study. However, we failed to show improvement in exertional dyspnea during the 6MWT in contrast to significant improvement during the modified incremental shuttle walk test. This discrepancy may be due to the psychometric characteristics of the outcome measures. Thus, the 6MWT is a submaximal and self-paced field test; however, the modified incremental shuttle walk test is a maximal and paced walking test. ${ }^{16,19}$ Although the subjects included in our study had less dyspnea perception, investigating the effects of inspiratory muscle training in patients with severe dyspnea will be useful in future studies.

\section{Quality of Life}

Sarcoidosis is a chronic, multisystem disorder and commonly affects young adults. The symptoms of sarcoidosis 
vary and may cause working and social problems. A number of studies also showed impaired quality of life and related symptoms in subjects with sarcoidosis. ${ }^{8}$ In the literature, studies have shown that inspiratory muscle training improves quality of life in subjects with COPD, ${ }^{11}$ bronchiectasis, ${ }^{13}$ cystic fibrosis, ${ }^{14}$ and heart failure. ${ }^{15}$ Although there were improvements in all subgroups and total scores of SGRQ in both groups with a large effect size, no significant improvement was observed between groups (with low statistical power). The effects of inspiratory muscle training on quality of life should be investigated in a larger population of subjects with sarcoidosis.

\section{Limitations}

Static lung volumes are the most affected parameters of pulmonary function in sarcoidosis patients. Because of technical problems during the study, most of the subjects' static lung volumes could not be measured. The study population was limited to subjects with stage I-II of sarcoidosis. We could not include patients in stage III-IV because they were not referred. It is inappropriate to generalize the results of this study to patients in later stages. Unfortunately, we did not evaluate the subjects' physical activity levels, which may be affected by inspiratory muscle training; this parameter should be included as an outcome in further studies.

\section{Conclusions}

A 6-week inspiratory muscle training program was an effective, feasible, and safe pulmonary physiotherapy method in subjects with early stages of sarcoidosis and improved exercise capacity and respiratory muscle strength while decreasing severe fatigue and dyspnea perception. However, inspiratory muscle training does not seem to have an impact on pulmonary function and diffusing capacity, peripheral muscle strength, fatigue, depression, and quality of life, at least at this intensity and duration. The optimal and appropriate training duration, frequency, and work load of inspiratory muscle training on patient populations has not yet been accurately detected. Multi-center studies should be planned to validate our results. Our study included early stages and subjects with milder pulmonary function abnormalities; thus, further studies to investigate the effects of inspiratory muscle training in later stages of sarcoidosis with severe pulmonary function limitations will be beneficial.

\section{ACKNOWLEDGMENTS}

We are very grateful to Murat Atan (Gazi University Faculty of Economics and Administrative Sciences) for reviewing the manuscript and providing advice regarding statistical analysis.

\section{REFERENCES}

1. Hunninghake GW, Costabel U, Ando M, Baughman R, Cordier JF, du Bois R, et al. ATS/ERS/WASOG statement on sarcoidosis. American Thoracic Society/European Respiratory Society/World Association of Sarcoidosis and other Granulomatous Disorders. Sarcoidosis Vasc Diffuse Lung Dis 1999;16(2):149-173.

2. Spruit MA, Thomeer MJ, Gosselink R, Troosters T, Kasran A, Debrock AJ, et al. Skeletal muscle weakness in patients with sarcoidosis and its relationship with exercise intolerance and reduced health status. Thorax 2005;60(1):32-38.

3. Baughman RP, Sparkman BK, Lower EE. Six-minute walk test and health status assessment in sarcoidosis. Chest 2007;132(1):207-213.

4. Kabitz HJ, Lang F, Walterspacher S, Sorichter S, Müller-Quernheim $\mathrm{J}$, Windisch W. Impact of impaired inspiratory muscle strength on dyspnea and walking capacity in sarcoidosis. Chest 2006;130(5): 1496-1502.

5. Baydur A, Alsalek M, Louie SG, Sharma OP. Respiratory muscle strength, lung function, and dyspnea in patients with sarcoidosis. Chest 2001;120(1):102-108.

6. Wirnsberger RM, Drent M, Hekelaar N, Breteler MH, Drent S, Wouters EF, Dekhuijzen PN. Relationship between respiratory muscle function and quality of life in sarcoidosis. Eur Respir J 1997;10(7): 1450-1455.

7. Lynch JP 3rd, Ma YL, Koss MN, White ES. Pulmonary sarcoidosis. Semin Respir Crit Care Med 2007;28(1):53-74.

8. De Vries J, Wirnsberger RM. Fatigue, quality of life and health status in sarcoidosis. In: Drent M, Costabel U, editors. Sarcoidosis. European Respiratory Monograph, Vol 10. Wakefield, UK: Informa; 2005:92-104.

9. Drent M, Wirnsberger RM, Breteler MH, Kock LM, de Vries J, Wouters EF. Quality of life and depressive symptoms in patients suffering from sarcoidosis. Sarcoidosis Vasc Diffuse Lung Dis 1998; 15(1):59-66.

10. Gosselink R, De Vos J, van den Heuvel SP, Segers J, Decramer M, Kwakkel G. Impact of inspiratory muscle training in patients with COPD: what is the evidence? Eur Respir J 2011;37(2):416-425.

11. Geddes EL, O'Brien K, Reid WD, Brooks D, Crowe J. Inspiratory muscle training in adults with chronic obstructive pulmonary disease: an update of a systematic review. Respir Med 2008;102(12): 1715-1729.

12. Silva IS, Fregonezi GA, Dias FA, Ribeiro CT, Guerra RO, Ferreira GM. Inspiratory muscle training for asthma. Cochrane Database Syst Rev 2013;(9):CD003792.

13. Liaw MY, Wang YH, Tsai YC, Huang KT, Chang PW, Chen YC, Lin MC. Inspiratory muscle training in bronchiectasis patients: a prospective randomized controlled study. Clin Rehabil 2011;25(6): 524-536.

14. Houston BW, Mills N, Solis-Moya A. Inspiratory muscle training for cystic fibrosis. Cochrane Database Syst Rev 2013;(11):CD006112.

15. Montemezzo D, Fregonezi GA, Pereira DA, Britto RR, Reid WD. Influence of inspiratory muscle weakness on inspiratory muscle training responses in chronic heart failure patients: a systematic review and meta-analysis. Arch Phys Med Rehabil 2014;95(7):1398-1407.

16. ATS Committee on Proficiency Standards for Clinical Pulmonary Function Laboratories. ATS statement: guidelines for the six-minute walk test. Am J Respir Crit Care Med 2002;166(1):111-117.

17. Gibbons WJ, Fruchter N, Sloan S, Levy RD. Reference values for a multiple repetition 6-minute walk test in healthy adults older than 20 years. J Cardiopulm Rehabil 2001;21(2):87-93.

18. Holland AE, Hill CJ, Conron M, Munro P, McDonald CF. Small changes in six-minute walk distance are important in diffuse parenchymal lung disease. Respir Med 2009;103(10):1430-1435.

19. Bradley J, Howard J, Wallace E, Elborn S. Validity of a modified shuttle walk test in adult cystic fibrosis. Thorax 1999;54(5):437-439. 


\section{Inspiratory Muscle Training in SARcoidosis}

20. Probst VS, Hernandes NA, Teixeira DC, Felcar JM, Mesquita RB, Gonçalves CG, et al. Reference values for the incremental shuttle walking test. Respir Med 2012;106(2):243-248.

21. American Thoracic Society/European Respiratory Society. ATS/ERS Statement on respiratory muscle testing. Am J Respir Crit Care Med 2002;166(4):518-624.

22. Evans JA, Whitelaw WA. The assessment of maximal respiratory mouth pressures in adults. Respir Care 2009;54(10):1348-1359.

23. Bohannon RW. Reference values for extremity muscle strength obtained by hand-held dynamometry from adults aged 20 to 79 years. Arch Phys Med Rehabil 1997;78(1):26-32.

24. American Thoracic Society. Lung function testing: selection of reference values and interpretative strategies (editorial). Am Rev Respir Dis 1991;144(5):1202-1218.

25. Quanjer PH, Tammeling GJ, Cotes JE, Pedersen OF, Peslin R, Yernault JC. Lung volumes and forced ventilatory flows: Report Working Party Standardization of Lung Function Tests, European Community for Steel and Coal: Official Statement of the European Respiratory Society. Eur Respir J Suppl 1993;16:5-40.

26. American Thoracic Society. Single breath carbon monoxide diffusing capacity (transfer factor): recommendations for a standard technique-1995 update (editorial). Am J Respir Crit Care Med 1995; 152(6):2185-2198.

27. Armutlu K, Korkmaz NC, Keser I, Sumbuloglu V, Akbiyik DI, Guney Z, Karabudak R. The validity and reliability of Fatigue Severity Scale in Turkish multiple sclerosis patients. Int J Rehabil Res 2007;30(1):81-85.

28. Mahler DA, Wells CK. Evaluation of clinical methods for rating dyspnea. Chest 1988;93(3):580-586.

29. Ozer SK, Demir B, Tugal O, Kabakci E, Yazici MK. Montgomery and Asberg Depression Rating Scale: interrater validity and reliability study. Turk Psikiyatri Derg 2001;12(3):185-194.

30. Polatlı M, Yorgancıoğlu A, Aydemir Ö, Yılmaz Demirci N, Kırkıl G, Atış Naycı S, et al. Validity and reliability of Turkish version of St. George's respiratory questionnaire. Tuberk Toraks 2013;61(2): 81-87.
31. McConnell A. Respiratory muscle training: theory and practice. Toronto: Elsevier; 2013:135-147.

32. Gosselink R, Wagenaar RC, Decramer M. Reliability of a commercially available threshold loading device in healthy subjects and in patients with chronic obstructive pulmonary disease. Thorax 1996; 51(6):601-605.

33. Erdfelder E, Faul F, Buncher A. GPOWER: a general power analysis program. Behavior Research Methods, Instruments, \& Computers 1996;28(1):1-11.

34. Stuessi C, Spengler CM, Knöpfli-Lenzin C, Markov G, Boutellier U. Respiratory muscle endurance training in humans increases cycling endurance without affecting blood gas concentrations. Eur J Appl Physiol 2001;84(6):582-586.

35. Sánchez Riera H, Montemayor Rubio T, Ortega Ruiz F, Cejudo Ramos P, Del Castillo Otero D, Elias Hernandez T, Castillo Gomez J. Inspiratory muscle training in patients with COPD: effect on dyspnea, exercise performance and quality of life. Chest 2001;120(3): 748-756.

36. Bosnak-Guclu M, Arikan H, Savci S, Inal-Ince D, Tulumen E, Aytemir K, Tokgözoglu L. Effects of inspiratory muscle training in patients with heart failure. Respir Med 2011;105(11):1671-1681.

37. Laoutaris ID, Adamopoulos S, Manginas A, Panagiotakos DB, Kallistratos MS, Doulaptsis C, et al. Benefits of combined aerobic/resistance/inspiratory training in patients with chronic heart failure: a complete exercise model? a prospective randomised study. Int J Cardiol 2013;167(5):1967-1972.

38. Santana-Sosa E, Gonzalez-Saiz L, Groeneveld IF, Villa-Asensi JR, Barrio Gómez de Aguero MI, Fleck SJ, et al. Benefits of combining inspiratory muscle with "whole muscle" training in children with cystic fibrosis: a randomized controlled trial. Br J Sports Med 2014; 48(20):1513-1517.

39. Enright S, Chatham K, Ionescu AA, Unnithan VB, Shale DJ. Inspiratory muscle training improves lung function and exercise capacity in adults with cystic fibrosis. Chest 2004;126(2):405-411.

40. Hill K, Jenkins SC, Philippe DL, Cecins N, Shepherd KL, Green DJ et al. High-intensity inspiratory muscle training in COPD. Eur Respir J 2006;27(6):1119-1128. 